\title{
Manifesting of pedagogical content knowledge on trigonometry in teachers' practice
}

\author{
Erica Dorethea Spangenberg \\ University of Johannesburg, South Africa
}

\begin{abstract}
Although trigonometry is an important section in secondary school mathematics curricula, many teachers find it challenging to teach as a result of insufficient pedagogical content knowledge (PCK). Therefore, the aim of this article was to report on how PCK on trigonometry manifests itself in teachers' practice. This exploratory case study was underpinned by the mathematics knowledge for teaching (MKT) model of Hill et al. (2008). Twelve teachers were purposefully selected from six township schools. Qualitative data were collected through semi-structured one-on-one interviews, lesson plans, assessment tasks, and lesson observations; and analyzed using content analysis. The findings show that four elements of PCK on trigonometry manifest themselves in teachers' practice, namely knowledge of subject matter, knowledge of teaching strategies, knowledge of students' conceptions and knowledge of curriculum, but varied in levels of sufficiency. Awareness of these variances forms a useful basis for planning developmental opportunities that could address shortcomings in PCK on trigonometry in teachers' practice. This study adds to few studies in PCK in mathematics by providing empirical evidence on how PCK on trigonometry manifests itself in teachers' practice.
\end{abstract}

Keywords: Pedagogical content knowledge (PCK); Trigonometry; Teachers; Mathematics

Article History: Submitted 23 May 2021; Revised 26 July 2021; Published online 24 August 2021

\section{Introduction}

Several researchers (Yang \& Sianturi, 2017; Fiallo \& Gutiérrez, 2017) have postulated that trigonometry is an important section in secondary school mathematics curricula because it links algebraic, geometric, and graphical reasoning; and is a precursor to calculus. Specifically, in South Africa, the context of this study, trigonometry is offered to students in the Further Education and Training (FET) phase and covers topics such as trigonometric ratios, reduction formulae, trigonometric identities, sine and cosine rules, trigonometric equations, double and compound angles, and trigonometric graphs (Department of Basic Education [DBE], 2011). Trigonometry comprises a large section of the grade 12 mathematics syllabus as it counts approximately 40 marks in the second final examination paper of this grade (DBE, 2011).

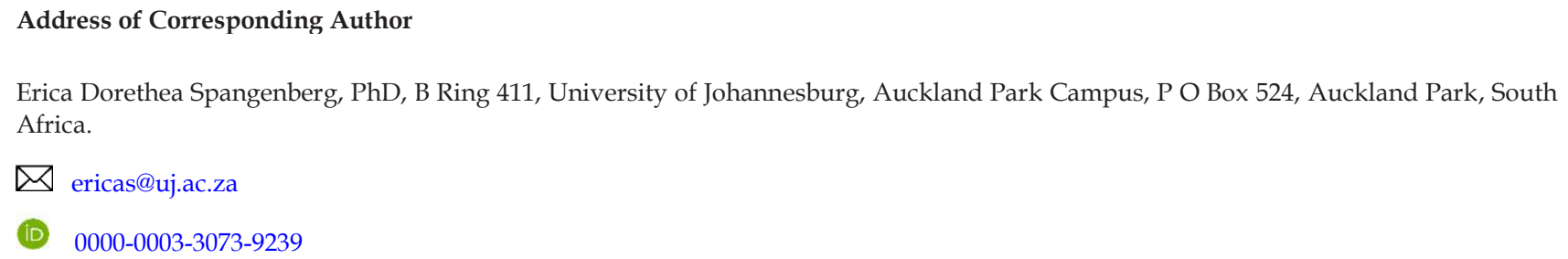

How to cite: Spangenberg, E. D. (2021). Manifesting of pedagogical content knowledge on trigonometry in teachers' practice. Journal of Pedagogical Research, 5(3), 135-163. https:/ / doi.org/10.33902/JPR.2021371325 
Due to the prominence of trigonometry in the mathematics syllabus and its applicability in different fields such as teaching of conjecture and proof in school geometry (Fiallo \& Gutiérrez, 2017), it is important that teachers should have an all-inclusive understanding of trigonometry to be able to connect and present different trigonometrical concepts (Rittle-Johnson \& Schneider, 2014). In particular, teachers' pedagogical content knowledge (PCK) is a reliable predictor of what they know and actually do in the classroom (Keller et al., 2017). Similarly, Kleickmann et al. (2015) posit that PCK influences key aspects of teaching quality, such as student gains in understanding mathematics. PCK is an element of teacher knowledge that relates to specific sections that are taught in schools and is an ingredient of teacher competence.

However, trigonometry is a section that teachers often find difficult to unpack for students to understand fully and consequently tend to oversimplify it to students (Sampaio Figueiredo \& Batista, 2018). Specifically, in South Africa, some teachers' lack of appropriate depth in PCK contributes towards students' underachievement in certain mathematics sections such as trigonometry (Brijlall \& Maharaj, 2014). Yet, mathematics researchers have not given sufficient attention to how the elements of PCK on trigonometry manifest itself in teachers' practice (Depaepe et al., 2013; Şimşek \& Boz, 2016).

Many scholars (Aydin et al., 2014; Campbell et al., 2014; Hill et al., 2008; Kleickmann et al., 2013; Loewenberg Ball et al., 2008) have studied teachers' PCK in terms of its elements such as knowledge of students' misconceptions, knowledge of content, and knowledge of the curriculum. The most prominent PCK model in the field of mathematics education is the mathematical knowledge for teaching (MKT) coined by Hill et al. (2008) that classifies teacher knowledge into two strands, namely subject matter knowledge and PCK. For this article, the focus is on the second strand, namely PCK. Unfortunately, the MKT model is a generic model that does not address topic-specific PCK in mathematics, such as trigonometry.

Depaepe et al. (2013) reviewed 60 articles on how PCK is conceptualized in mathematics education research and identified six research lines: (1) the nature of teachers' PCK, (2) content knowledge (CK) versus PCK, (3) PCK and teaching practice, (4) PCK and mathematics performance, (5) PCK and personal attributes, and (6) PCK development of teachers. They asserted that both pre-service and in-service teachers' have PCK gaps in a variety of mathematics topics, such as functions, fractions, and problem solving. However, trigonometry was not among the mathematics sections that were investigated by researchers in the sampled articles. Şimşek and Boz (2016), in a meta-synthesis of mathematics PCK studies in Turkey, also found that trigonometry is a section not being investigated often within PCK studies. A study on PCK in mathematics in South Africa conducted by Brijlall and Maharaj (2014) ascertained that the quality of in-service teachers' PCK affects student performance in mathematics. They focused specifically on teachers' PCK on trigonometry, algebra, and calculus in low performing (LP) schools and found that teachers need PCK development on trigonometry.

From the above studies, it is clear that research on in-service teachers' PCK to advance teaching sections such as trigonometry is limited. With this study, the intention is not only to contribute to research on topic-specific PCK in mathematics, but also to establish how PCK on trigonometry manifests itself in teachers' practice, which is the purpose of this paper. The authors amended the MKT model to investigate how the following elements of PCK on trigonometry manifested themselves in teachers' practice: (1) knowledge of subject matter (KSM), (2) knowledge of teaching strategies (KTS), (3) knowledge of students' conceptions (KSC), and (4) knowledge of the curriculum (KC). Awareness of variances in levels of sufficiency between these elements in teachers' practice, if any, could form a useful basis for planning developmental opportunities addressing such shortcomings in teachers' practice.

\subsection{Elements of PCK}

PCK as a construct was coined by Shulman (1986) in an attempt to establish that teaching is a profession. The way of recognizing the knowledge base of teaching lies at the convegence of the 
CK and the teaching method. Shulman (1987) further argued that teachers must have the ability to change the subject content into structures that are understandable to their students. Thus, teachers need to develop PCK at an appropriate level to support students to succeed in their learning of trigonometry.

Mishra and Koehler (2006) view PCK as an information base that is concerned about portraying and defining ideas, educational procedures, and information; what make these ideas problematic or simple to learn; and knowledge of students' former experiences with these ideas. Rollnick et al. (2008) add context to the blend of subject matter knowledge an pedagogy. Similarly, Kleickmann et al. (2015) view PCK as a dimension of teacher knowledge that is directly connected to the content topics taught within the school curriculum. However, all these different definitions can be traced back to Shulman's (1986) definition in that PCK is the special knowledge base that makes teaching a profession.

The MKT model of Hill et al. (2008), used as the conceptual lens for this study, resulted from an extensive analysis of mathematics teaching practice, to modify and validate Shulman's concept of PCK empirically (Depaepe et al., 2013). Unfortunately, the MKT model was conceptualized for primary school teachers and underestimates the PCK development of high school teachers (Hauk et al., 2014; Speer et al., 2015). Nevertheless, Depaepe et al. (2013) consider the MKT model to be a more persuasive reconceptualization of the PCK of teachers within the mathematics education community since the inception of the PCK construct. Also, MKT relates to teachers' daily attempts to engage students in the learning of mathematics (Phelps \& Howell, 2016) and therefore the author views this model as suitable to establish how PCK on trigonometry manifests itself in teachers' practice.

The MKT model consists of two strands, namely subject matter knowledge and PCK, which are also foregrounded by Shulman (1987). Subject matter knowledge is further sub-divided into three sub-categories: (1) common CK; (2) specialized CK; and (3) horizon CK. In the context of this study, common CK is the mathematical knowledge possessed by a teacher with regard to the trigonometrical concepts. Specialized CK refers to the focused nature of trigonometrical knowledge in teachers' practice as opposed to the knowledge required by other professionals that uses trigonometry. Horizon $\mathrm{CK}$ is the awareness of how trigonometric concepts are connected from one grade to the next.

The strand PCK in the MKT model, which is the focus of this study, is also sub-divided into three sub-categories (Hill et al., 2008). First, knowledge of content and students signifies to the teacher's capacity to foresee the trigonometrical concepts that will strike the students as easy, challenging, interesting or motivating (Carrillo-Yañez et al., 2018). However, for this study, knowledge of content and students were separated as KSM displayed by teachers in teaching trigonometry; and the knowledge of knowledge of students' conceptions and misconceptions (KSC). KSC refers specifically to teachers' understanding of how students learn particular sections such as trigonometry (Şahin et al., 2016). Secondly, knowledge of content and teaching denotes to teachers' knowledge of the ways of presenting trigonometrical concepts, principles, procedures, and relationships between these; and reasons for using them in order for students to comprehend (Şahin et al., 2016). For this study, knowledge of content and teaching was amended to knowledge of teaching strategies (KTS) applied in teaching trigonometry; and knowledge of students' conceptions and misconceptions (KSC). Lastly, KC, also adopted for this study, implies an awareness of the learning outcomes, subject content, teaching-and-learning activities, resources, and assessments to foreground in the teaching of trigonometry as specified in the mathematics curriculum.

Thus, four elements of PCK for teachers adapted from the MKT model were adopted for this study: KSM; KTS; KSC; and KC. These four elements align well with the elements of the MKT model as discussed next. 


\subsubsection{Knowledge of Subject Matter}

KSM is a major pillar of the MKT model. KSM defines the depth of mathematics content a teacher possesses that will be transferred to students. For this study, KSM involves teachers' understanding of the trigonometrical concepts and the procedures of unpacking them for students to comprehend.

Students' performance depends on the level at which the teacher comprehends the trigonometrical concepts, procedures, and formulae (Depaepe et al., 2013). According to Baumert et al. (2010), the breadth and depth of teachers' KSM determine the variety of teaching strategies and the types of alternative mathematical representations teachers will use in their teaching of a particular topic to students (Baumert et al., 2010) as well as how they will link topics across different grades (Walsh et al., 2017). Insufficient KSM reduces teachers' competence to clarify and represent mathematics content to students in a meaningful way or to offer students opportunities to effectively engage with mathematics content (Baumert et al., 2010).

KSM is often claimed an important variable for PCK development and necessary for effective teaching. Specifically, teachers' understanding of trigonometry, knowledge of its structure and order of concepts, and possession of good conceptual and procedural knowledge are essential to steer students into the ways of knowing that trigonometry offers, whereas a lack of KSM can impede teachers' PCK development (Chan \& Yung, 2018). Teachers' cannot teach what they do not know. Students can only learn trigonometry if teachers have a sound knowledge of the content they will be teaching. In particular, teachers' subject matter knowledge informs their strategies to use in their teaching of trigonometry. Ball (2000) also revealed that teachers only use different pedagogies in their teaching of specific mathematics topics if they have well-developed conceptual KSM. The comprehension of basic subject matter concepts by teachers depends on teachers' instruction experiences supported by well-designed professional development programs (Aydin et al., 2014). Consequently, KSM serves as a tool for teachers to teach trigonometry and, in turn, successful teaching depends on teachers' level of PCK on trigonometry regarding KSM.

\subsubsection{Knowledge of Teaching Strategies}

KTS relates to knowledge of content and teaching in the MKT model and refers to knowledge of different methods to teach and unpack mathematical content (Chick \& Beswick, 2018; Şahin et al., 2016). For this study, KTS involved the techniques that teachers used in their teaching as they described, demonstrated, and unpacked the trigonometric concepts for comprehension by students.

O'Meara et al. (2017) argue that ineffective teaching strategies utilizing memorization and focusing on procedural skills with no thought for conceptual understanding are challenging to change. Therefore, teachers must know which teaching strategies contribute to students' understanding of how and why certain steps are taken to solve a trigonometry problem (Goodnough et al., 2019). The teaching of trigonometry content must flow logically for students to comprehend the concepts. Holtman et al. (2018) recommend that teachers should use studentcentered strategies to ensure conceptual understanding of mathematics by students. In addition, both Law et al. (2015) and Mutodi and Ngirande (2014) agree that exposing students to the real-life applications of a mathematics topic like trigonometry enhances students' conceptual understanding.

According to Wong et al. (2012) by using real-life examples, teachers are not only advancing students' critical thinking skills, but are also developing their own higher order knowledge. Although trigonometry may not have explicit applications in solving practical problems, it is widely used in engineering, architecture, music, and industry to describe the relationship between angles and lengths of triangles. For example, trigonometry is often used to determine angles of elevation for heights of buildings, angles of depression for depths of underground systems, or roof inclination. Trigonometry also plays a major role in flight engineering to navigate planes using sine, cosine or area rules, and in the music production where sound waves are displayed 
graphically by sine and cosine functions. To introduce real-life examples into the teaching of trigonometry, Gould and Schmidt (2010) suggested that students be asked to design simulated word problems about real-life situations and apply trigonometric functions to solve them. Gerhana et al. (2017) added that project-based learning utilizing group work to investigate real-life problems, which align with the requirements of the curriculum and may be interdisciplinary, is an effective strategy to teach trigonometry. Another method to make trigonometry meaningful, according to Carson (2017), is to review the history on discoveries on measurement of chords in circles and properties of triangles, and then map that with trigonometric content prescribed in the curriculum. Nevertheless these examples, teachers need to select teaching strategies appropriate for the content they will teach to ensure maximum learning by students, but also to develop KTS.

\subsubsection{Knowledge of Student Conceptions}

KSC relates to knowledge of content and students in the MKT model and refers to teachers' understanding of how students learn mathematics (Hill et al., 2008; Şahin et al., 2016). KSC also encompasses the mistakes and misconceptions that usually arise in the process of teaching trigonometry (Goodnough et al., 2019). For this study, KSC connects students' conceptions about trigonometry to the way subject content is unpacked to the students.

Teachers must identify what students think about certain trigonometrical concepts and what might lead students to being confused with the content (Appova \& Taylor 2020) when planning lessons. Therefore, it is important for teachers to reflect during lesson planning for action during teaching by connecting the lesson plan with the intended goal of the lesson (Olteanu, 2017). Furthermore, teachers who have good KSC are able to identify students' misconceptions, which is key for effective mathematics teaching (Wilson et al., 2005). However, due to minimum contact time in the classroom, many teachers just glance at students' work without allowing them to get a full picture of the effects of their teaching on students' comprehension of trigonometry. To develop KSC, it is therefore imperative for teachers to set time aside to reflect on their students' ways of thinking and learning difficulties; and purposively elicit students' prior knowledge about trigonometry.

\subsubsection{Knowledge of Curriculum}

$\mathrm{KC}$ is an element of the MKT model that merges knowledge about mathematics content with that of the curriculum. Thus, KC indicates a teacher's view of trigonometry relative to the entire mathematics curriculum. However, teachers' views towards teaching and learning of mathematics can impede their understanding of the curriculum if they are not aligned with the framing of the curriculum (Chapman, 2012). Thus, teachers should have KC that are in harmony with the goals of the curriculum and should have knowledge of relevant resources; and how to sequence trigonometry concepts across the grade and the various topics (Appova \& Taylor, 2020) to ensure effective teaching of trigonometry. Hence, for this study, KC refers to teachers' understanding of the entire mathematics curriculum as it relates to trigonometry; and the mastery of the materials and programs associated with the curriculum. The curriculum informs teachers of the content to be taught at each level, and, consequently, teachers must have KC to be able to unpack the content prescribed in the curriculum for students (Ogbonnaya \& Mogari, 2014). In South Africa, teachers must know the trigonometrical concepts covered within the particular phase, but also the specifications of the Curriculum and Assessment Policy Statements (CAPS) document (DBE, 2011) about the topic. The CAPS document determines the depth and breadth with regard to the concepts that must be covered in each grade.

\subsection{Research Question}

As trigonometry is an important section in secondary school mathematics curricula and teachers need well-developed PCK to teach it, but research in this area is limited, the following research question was formulated: How does PCK on trigonometry manifest itself in teachers' practice? The following sub-questions informed the research question: 
- What are teachers' perceptions of the elements of PCK required for effective teaching of trigonometry?

- What elements of PCK manifest in teachers' lesson plans on trigonometry?

- What elements of PCK manifest during teaching of trigonometry?

- What elements of PCK manifest in teachers' assessment tasks on trigonometry?

\section{Research Methodology}

This study adopted an exploratory qualitative case study. Although the data collected were qualitative in order to draw conclusions, some qualitative data were also quantified (Lee et al., 2019) to strengthen the categorization of the elements of PCK pertaining to the level of alignment with the MKT model. Six township secondary schools in the Ekurhuleni North District in Gauteng Province of South Africa consisting of both high and LP schools were purposively selected. A township is considered as a residential area comprising low cost formal houses and informal settlements where residents are black, schools are non-fee paying, and students are given free lunch (Krause \& Prinsloo, 2016). High performing (HP) schools obtained an average pass rate of above $80 \%$ in grade 12 mathematics, while LP schools had an average pass rate of below $60 \%$ for four consecutive years. All six schools were government public schools with both boys and girls. Two teachers per school, thus twelve teachers in total, were purposively selected based on the following criteria: Easy access; availability; voluntarily participation; and teaching FET mathematics for at least three consecutive years.

The participants' teaching experience ranged from 4 to 34 years, and their qualifications varied from teachers' diplomas (four teachers), B Ed degrees (seven teachers), and master's degrees (one teacher). There were seven male teachers and five female teachers.

\subsection{Data Collection Tools}

Data were collected by means of interviews, documents (lesson plans and assessment tasks), and lesson observations. Semi-structured one-on-one interviews were conducted to identify the participants' perceptions about the elements of PCK on trigonometry. The interview questions included questions about KSM, KTS, KSC, and KC. The interviews took place on the same day, but prior to the lesson observation, and were audio recorded and transcribed. All twelve participants were interviewed.

Twenty-four lesson plans (two from each participant of the lessons observed) were used to establish the elements of PCK that were manifested in the lesson plans on trigonometry. The participants were expected to use the prescribed template of the DBE to design their lessons, which includes the following aspects: (1) the aim of the lesson; (2) skills and knowledge to acquire; (3) forms and tools for assessment; (4) the learning context focusing on prior knowledge and differentiation; (5) resources; (6) teaching strategies; and (7) opportunities for reflection. Although the lesson plan template does not pertinently make provision for teachers to reflect on possible misconceptions, it expects that teachers should include accommodations and/or modifications to ensure inclusion of all students.

The participants were requested to design any two consecutive lessons focusing on trigonometry in the FET phase (grades 10-12). As participation was voluntarily and lesson observations had to be scheduled according to various schools' programs, the lesson plans did not focus on the same trigonometry topics, but the topics were according to those prescribed in the CAPS document. The progression in terms of contents also varied from school to school. The lesson plans were submitted after the lesson observations and retyped.

Non-participant lesson observations using a lesson observation protocol were used to ascertain the level of sufficiency of PCK that manifests itself during the teaching of trigonometry. The lesson observation took place from May to August at schools during teaching periods of 40-55 minutes. The lesson observation protocol assisted the researcher to capture the participants' engagement in teaching with minimum interference. The focus of the lessons observed is displayed in Table 1. 
Table 1

Lesson Observation Schedule

\begin{tabular}{|c|c|c|c|c|}
\hline School & Participant & Date of observation & Grade & Focus of lesson \\
\hline \multirow{4}{*}{1} & $1 \mathrm{~A}$ & 22 July & 12 & Proof and use of the compound angle identities \\
\hline & $1 \mathrm{~A}$ & 23 July & 12 & Proof and use of the double angle identities \\
\hline & 1B & 22 July & 11 & $\begin{array}{l}\text { Derive and use the identities: } \\
\tan \theta=\frac{\sin \theta}{\cos \theta} \text { and } \sin ^{2} \theta+\sin ^{2} \theta=1\end{array}$ \\
\hline & 1B & 23 July & 11 & Derive the reduction formulae \\
\hline \multirow{4}{*}{2} & $2 \mathrm{~A}$ & 16 August & 12 & Proof and use of the compound angle identities \\
\hline & $2 \mathrm{~A}$ & 16 August & 12 & Proof and use of the double angle identities \\
\hline & $2 B$ & 16 August & 11 & $\begin{array}{l}\text { Derive and use the identities: } \\
\tan \theta=\frac{\sin \theta}{\cos \theta}\end{array}$ \\
\hline & $2 B$ & 18 August & 11 & $\begin{array}{l}\text { Derive and use the identities: } \\
\sin ^{2} \theta+\sin ^{2} \theta=1\end{array}$ \\
\hline \multirow{4}{*}{3} & $3 \mathrm{~A}$ & 31 July & 10 & $\begin{array}{l}\text { Definitions of the trigonometric ratios } \sin \theta, \cos \theta \\
\text { and } \tan \theta \text { in a right-angled triangles }\end{array}$ \\
\hline & $3 \mathrm{~A}$ & 2 August & 0 & $\begin{array}{l}\text { Extend the definitions of } \sin \theta, \cos \theta \text { and } \tan \theta \text { to } \\
0^{\circ} \leq \theta \leq 360\end{array}$ \\
\hline & 3B & 31 July & 11 & $\begin{array}{l}\text { Derive and use the identities: } \\
\tan \theta=\frac{\sin \theta}{\cos \theta} \text { and } \sin ^{2} \theta+\sin ^{2} \theta=1\end{array}$ \\
\hline & 3B & 2 August & 11 & Derive the reduction formulae \\
\hline \multirow{4}{*}{4} & $4 \mathrm{~A}$ & 24 May & 11 & $\begin{array}{l}\text { Derive and use the identities: } \\
\tan \theta=\frac{\sin \theta}{\cos \theta} \text { and } \sin ^{2} \theta+\sin ^{2} \theta=1\end{array}$ \\
\hline & $4 \mathrm{~A}$ & 28 May & 11 & Derive the reduction formulae \\
\hline & 4B & 24 May & 12 & Proof and use of the compound angle identities \\
\hline & 4B & 28 May & 12 & Proof and use of the double angle identities \\
\hline \multirow{6}{*}{5} & $5 \mathrm{~A}$ & 17 July & 10 & $\begin{array}{l}\text { Definitions of the trigonometric ratios } \sin \theta, \cos \theta \\
\text { and } \tan \theta \text { in a right-angled triangles }\end{array}$ \\
\hline & $5 \mathrm{~A}$ & 19 July & 10 & $\begin{array}{l}\text { Extend the definitions of } \sin \theta, \cos \theta \text { and } \tan \theta \text { to } \\
0^{\circ} \leq \theta \leq 360^{\circ}\end{array}$ \\
\hline & $5 B$ & 17 July & 11 & $\begin{array}{l}\text { Derive and use the identities: } \\
\tan \theta=\frac{\sin \theta}{\cos \theta} \text { and } \sin ^{2} \theta+\sin ^{2} \theta=1\end{array}$ \\
\hline & $5 \mathrm{~B}$ & 19 July & 11 & Derive the reduction formulae \\
\hline & $5 \mathrm{C}$ & 17 July & 10 & $\begin{array}{l}\text { Definitions of the trigonometric ratios } \sin \theta, \cos \theta \\
\text { and } \tan \theta \text { in a right-angled triangles }\end{array}$ \\
\hline & $5 \mathrm{C}$ & 19 July & 10 & $\begin{array}{l}\text { Extend the definitions of } \sin \theta, \cos \theta \text { and } \tan \theta \text { to } \\
0^{\circ} \leq \theta \leq 360^{\circ}\end{array}$ \\
\hline \multirow[t]{2}{*}{6} & $6 \mathrm{~A}$ & 23 July & 11 & $\begin{array}{l}\text { Derive and use the identities: } \\
\tan \theta=\frac{\sin \theta}{\cos \theta} \text { and } \sin ^{2} \theta+\sin ^{2} \theta=1\end{array}$ \\
\hline & $6 \mathrm{~A}$ & 30 July & 11 & Derive the reduction formulae \\
\hline
\end{tabular}

Twenty-four assessment tasks (two from each participant) in the form of classwork and homework given to the students were analyzed. The aim was to identify the elements of PCK present in the participants' assessment tasks on trigonometry.

To ensure credibility and rigorousness, triangulation and member checking were employed. The data were collected using multiple data sources such as one-on-one interviews, lesson observations, and documents to verify findings. 
The author and a research assistant first coded the data independently, where after the codes and the interpretation of the data were compared for agreement to minimize subjectivity. The percentage of exact agreement was established at $84 \%$, which revealed an acceptable interrater reliability.

A rich and thick report of the study (Merriam \& Tisdell, 2015), descriptions of demographics and geographic boundaries of the research, and how data were collected and analyzed were provided to replicate or amend the study to similar contexts. Direct quotations from the data were used to confirm that findings are based on the participants' narratives. Findings were also controlled against literature. To ensure confirmability, the researcher disclosed the research process and the limitations, and fulfilled the ethical requirements (Rule \& Vaughn, 2011). The authors' influences and bias on the findings of the study as researchers were also revealed. Ethical clearance was granted by the ethics committee of the university overseeing the study (Ethical clearance number 2017-098) and the Gauteng Department of Education, and ethical measures were adhered to.

\subsection{Data Analysis}

The data collected from the four data sources were analyzed using content analysis. Content analysis is a technique to categorize written or oral materials into identified groupings of similar meanings (Cho \& Lee, 2014). Five steps were followed to conduct content analysis. First, based on each of the sub-research questions, the data collection instruments were identified, namely (1) interviews; (2) lesson plans (documents); (3) lesson observation notes; (4) assessment activities (documents). The interviews were audio-recorded and transcribed. Secondly, the data collected from interview transcripts, observation notes, and documents were carefully read to obtain a holistic overview. The data were reread to establish relevant data. Redundant information was removed after consensus had been reached between the author and a research assistant. Together, individual words and phrases were inductively coded and their frequency was recorded as illustrated in Tables 2-5. Thirdly, these codes were grouped in sub-categories according to units of meaning. Fourthly, the sub-categories were organized into predefined categories derived from the MKT model, which informs the study, namely the four elements of PCK: KSM, KTS, KSC, and KC. This type of coding to analyze the elements' properties and to discover how they related to each other (Saldana, 2013) is also known as axial coding. Lastly, after completion of coding, the collected data were scrutinized to establish patterns and to make inferences in response to the subresearch questions. A cross-case analysis was done, which is an analysis to determine whether there are any common features among the elements of PCK manifested in teachers' practice (Cho \& Lee, 2014).

Data were analyzed in four phases. Phase 1 consisted of the analysis of the interviews, Phase 2 comprised the analysis of the lesson plans, Phase 3 focused on the analysis of the lesson observations, and Phase 4 concerned the analysis of the assessment tasks. For each phase, the authors created summary tables of the four elements of PCK transpired from each of the data collection instruments. Each table indicates the subcategories, codes, and frequencies of the occurrences of each code for the schools.

\section{Results}

The results from the analysis of the data collected from the interviews conducted during Phase 1 to establish teachers' perceptions of the elements of PCK required for effective teaching of trigonometry are illustrated according to the four elements of PCK in Table 2. The letter $f$ indicates the frequency reference was made to a concept that was taught in a lesson, while the letter $n$ indicates the number of participants (out of 12), who indicated that they will teach the corresponding concept. For example, there were seven responses to identities in total, which were made by four out of the twelve participants. 
Table 2

Data Analysis of the Interviews according to the Four Elements of PCK

\begin{tabular}{|c|c|c|c|c|}
\hline $\begin{array}{l}\text { Category } \\
\text { (Elements of } \\
\text { PCK) }\end{array}$ & Sub-categories & Codes & $\begin{array}{l}\text { Frequency of } \\
\text { occurrence } \\
(f)\end{array}$ & $\begin{array}{c}\text { Number of } \\
\text { participants } \\
n=12\end{array}$ \\
\hline \multirow{8}{*}{ KSM } & \multirow{5}{*}{ Key concepts } & Identities & 7 & 4 \\
\hline & & Reduction formula & 7 & 7 \\
\hline & & Equations & 5 & 3 \\
\hline & & Ratios & 5 & 5 \\
\hline & & Graphs & 0 & 0 \\
\hline & Concept map & Explanation & 24 & 12 \\
\hline & \multirow{2}{*}{$\begin{array}{l}\text { Procedural } \\
\text { knowledge }\end{array}$} & Involved & 22 & 11 \\
\hline & & Not involved & 2 & 1 \\
\hline Sub-total of $f$ & & & 72 & \\
\hline \multirow{6}{*}{ KTS } & \multirow{2}{*}{$\begin{array}{l}\text { Teaching } \\
\text { strategy }\end{array}$} & Teacher-centered & 8 & 4 \\
\hline & & Less teacher-centered & 16 & 8 \\
\hline & \multirow{2}{*}{$\begin{array}{l}\text { Reason for } \\
\text { selecting } \\
\text { strategy }\end{array}$} & Involve students & 16 & 8 \\
\hline & & Help students remember & 8 & 4 \\
\hline & \multirow{2}{*}{$\begin{array}{l}\text { Real-life } \\
\text { example }\end{array}$} & Practical examples & 1 & 1 \\
\hline & & Non-practical examples & 11 & 11 \\
\hline Sub-total of $f$ & & & 60 & \\
\hline \multirow{11}{*}{ KSC } & Goal of lesson & Clearly stated & 24 & 12 \\
\hline & \multirow{3}{*}{ Prior knowledge } & Ratios & 10 & 5 \\
\hline & & Equations & 2 & 1 \\
\hline & & Cartesian plane & 12 & 6 \\
\hline & \multirow{2}{*}{$\begin{array}{l}\text { Student } \\
\text { misconceptions }\end{array}$} & Misconceptions indicated & 7 & 3 \\
\hline & & Misconceptions not indicated & 18 & 9 \\
\hline & \multirow{3}{*}{$\begin{array}{l}\text { Assistance to } \\
\text { students with } \\
\text { difficulties }\end{array}$} & Extra classes & 18 & 9 \\
\hline & & $\begin{array}{l}\text { Re-explaining misunderstood } \\
\text { concepts }\end{array}$ & 4 & 5 \\
\hline & & Use clever students & 2 & 2 \\
\hline & \multirow{2}{*}{$\begin{array}{l}\text { Assessment } \\
\text { tasks }\end{array}$} & Past examination papers & 6 & 5 \\
\hline & & Classwork and homework & 24 & 12 \\
\hline Sub-total of $f$ & & & 126 & \\
\hline \multirow{5}{*}{$\mathrm{KC}$} & \multirow{3}{*}{$\begin{array}{l}\text { Link with other } \\
\text { topics }\end{array}$} & Coordinate geometry & 18 & 9 \\
\hline & & Euclidean geometry & 6 & 3 \\
\hline & & Algebra & 2 & 1 \\
\hline & \multirow{2}{*}{$\begin{array}{l}\text { Use of real-life } \\
\text { examples }\end{array}$} & Use practical examples & 4 & 2 \\
\hline & & No practical examples & 20 & 10 \\
\hline Sub-total of $f$ & & & 50 & \\
\hline Grand total of $f$ & & & 308 & \\
\hline
\end{tabular}

KSM involved the participants' understanding of the trigonometrical concepts and the procedures of unpacking them for the comprehension of the students. KTS involved the approaches and techniques that participants used in their teaching as they had described, demonstrated, and unpacked the trigonometric concepts for the maximum comprehension of the students. KSC involved the participants' understanding of the students' prior knowledge, the mistakes or misconceptions, and students' learning difficulties about trigonometry. $\mathrm{KC}$ referred to 
the participants' understanding of the full range of mathematical topics that are included at the FET phase and how they are connected to trigonometry.

Table 3 presents a summary of the results of the analysis of the data collected through the lesson plans during Phase 2 to identify the elements of PCK as manifested in teachers' lesson plans on trigonometry. The first column indicates the categories, namely the elements of PCK. The second column indicates the sub-categories for each of the elements of PCK. The sub-categories were taken from the questions corresponding to each PCK element. The total number of lesson plans obtained from the participants was 24 . The last column indicates the sum of the number of lessons indicating sub-categories of the elements of PCK.

Table 3

Data Analysis of Lesson Plans according to Four Elements of PCK

\begin{tabular}{|c|c|c|}
\hline $\begin{array}{l}\text { Category } \\
\text { (Elements of } \\
\text { PCK) }\end{array}$ & Sub-categories & $\begin{array}{l}\text { Total number of lesson plans } \\
\qquad n=24\end{array}$ \\
\hline \multirow{3}{*}{ KSM } & Key concepts indication & 22 \\
\hline & Indication of procedures & 22 \\
\hline & Reflection of concepts and procedures & 24 \\
\hline \multirow{3}{*}{ KTS } & Teaching strategy & 24 \\
\hline & Reflection of alternative strategy & 18 \\
\hline & Indication of examples & 16 \\
\hline \multirow{5}{*}{ KSC } & Reflection on misconceptions & 4 \\
\hline & Reflection on prior knowledge & 18 \\
\hline & Reflection on student difficulties & 0 \\
\hline & Indication of assessment task & 22 \\
\hline & Goal clearly stated & 24 \\
\hline \multirow{2}{*}{$\mathrm{KC}$} & Link with other topics & 24 \\
\hline & Fits trigonometry into curriculum & 0 \\
\hline
\end{tabular}

KSM was identified in terms of trigonometrical concepts and procedures for teaching the concepts evident in lesson plans. KTS was demonstrated in terms of the clarity and specificity of the teaching strategy to be used for the lesson. KSC was identified by participants' notes in their lesson plans of possible misconceptions in trigonometry and ways to eliminate the misconceptions. KC was evident in linking trigonometry with other topics and fitting trigonometry into the curriculum.

Table 4 displays a summary of the results of the analysis of data obtained through the lesson observations made for Phase 3 to ascertain the elements of PCK as manifested during their teaching of trigonometry. The sub-categories are phrases that were extracted from the observable practices and are displayed in the second column of the table. The number of observed lessons in which the sub-category was observed is indicated with $n_{0}$. The number $(n)$ gives the number of participants who displayed the sub-category. 
Table 4

Data Analysis of the Lesson Observation according to the Four Elements of PCK

\begin{tabular}{|c|c|c|c|}
\hline $\begin{array}{l}\text { Category } \\
\text { (Elements of PCK) }\end{array}$ & Sub-category & $\begin{array}{c}\text { Observed lessons } \\
n_{0}=12\end{array}$ & $\begin{array}{c}\text { Participants } \\
n=12\end{array}$ \\
\hline \multirow{4}{*}{ KSM } & Conceptual understanding & 18 & 9 \\
\hline & Fundamental concepts & 20 & 10 \\
\hline & Skillfully solves problems & 14 & 7 \\
\hline & Notices students' alternative methods & 2 & 1 \\
\hline \multirow{4}{*}{ KTS } & Uses appropriate activities & 24 & 12 \\
\hline & Uses real-life examples & 0 & 0 \\
\hline & Uses different strategies & 10 & 5 \\
\hline & Students share knowledge & 24 & 12 \\
\hline \multirow{4}{*}{ KSC } & Addresses misconceptions & 4 & 2 \\
\hline & $\begin{array}{l}\text { Displays expectations according to } \\
\text { students' performance }\end{array}$ & 4 & 2 \\
\hline & Discusses students' ways of thinking & 4 & 2 \\
\hline & Awareness of assessment task & 24 & 12 \\
\hline \multirow{3}{*}{$K C$} & $\begin{array}{l}\text { Connects trigonometry with other } \\
\text { topics }\end{array}$ & 14 & 7 \\
\hline & Fits trigonometry into curriculum & 10 & 5 \\
\hline & Links trigonometry vertically & 24 & 12 \\
\hline
\end{tabular}

KSM was manifested if participants exhibited a deep and thorough conceptual understanding of identified aspects of trigonometry. KTS involved knowing about the approaches for teaching trigonometrical concepts. KSC involved participants' understanding of students' prior knowledge, mistakes or misconceptions, and students' learning difficulties about trigonometry. KC referred to the participants' knowledge about the horizontal and vertical curricula of trigonometry.

Table 5 represents the results of the analysis of the data gathered from the assessment tasks according to the four elements of PCK during Phase 4 to detect the elements of PCK as manifested

Table 5

Data Analysis of the Assessment Tasks according to the Four Elements of PCK

\begin{tabular}{|c|c|c|c|c|}
\hline $\begin{array}{l}\text { Elements of } \\
\text { PCK }\end{array}$ & $\begin{array}{l}\text { Assessment } \\
\text { tasks }\end{array}$ & Sub-categories & $\begin{array}{c}\text { Assessments } \\
n_{a}=24\end{array}$ & $\begin{array}{c}\text { Participants } \\
n=12\end{array}$ \\
\hline \multirow{4}{*}{ KSM } & \multirow[b]{2}{*}{ Classwork } & Key concepts & 24 & 12 \\
\hline & & $\begin{array}{l}\text { Reflection of accurate trigonometry } \\
\text { concepts }\end{array}$ & 24 & 12 \\
\hline & \multirow[b]{2}{*}{ Homework } & Key concepts & 24 & 12 \\
\hline & & $\begin{array}{l}\text { Reflection of accurate trigonometry } \\
\text { concepts }\end{array}$ & 24 & 12 \\
\hline \multirow{4}{*}{ KTS } & \multirow{2}{*}{ Classwork } & Use of appropriate activities & 24 & 12 \\
\hline & & Use of real-life related tasks & 0 & 0 \\
\hline & \multirow{2}{*}{ Homework } & Use of appropriate activities & 24 & 12 \\
\hline & & Uses real-life related tasks & 0 & 0 \\
\hline \multirow{2}{*}{ KSC } & Classwork & Knowledge of student difficulties & 8 & 4 \\
\hline & Homework & Knowledge of student difficulties & 10 & 5 \\
\hline \multirow{4}{*}{$\mathrm{KC}$} & \multirow{2}{*}{ Classwork } & Links trigonometry vertically & 24 & 12 \\
\hline & & Use of real- life tasks & 0 & 0 \\
\hline & \multirow{2}{*}{ Homework } & Links trigonometry vertically & 24 & 12 \\
\hline & & Use of real-life related tasks & 0 & 0 \\
\hline
\end{tabular}


in teachers' assessment tasks on trigonometry. The first column contains the elements of PCK, the second column indicates the assessment tasks, and the third column indicates the sub-categories. The last columns represent the number of assessment tasks $\left(n_{a}\right)$ and the number of participants $(n)$ who made reference to the specific sub-category.

The results from the analysis of the data displayed in Tables 2-5 are discussed next. Each of the sub-questions is addressed according to the four categories considered for this study, namely KSM, KTS, KSC, and KC.

\subsection{Teachers' Perceptions of the Elements of PCK required for Effective Teaching of Trigonometry}

All the participants indicated some of the key concepts for the lessons they were going to teach, for example, trigonometric equations, reduction formulae, compound and double angle formulae, and trigonometric ratios. Participant 2A stated:

The key concepts are reduction formulae; double angle formula; trigonometric ratios.

Participant 5A agreed:

The key concepts are Theorem of Pythagoras, Cartesian plane, and trigonometric ratios, reduction formulae and complimentary angles.

The reason why the participants could indicate the key concepts of FET trigonometry may be that mathematics teachers are familiar with the concepts.

All the participants gave the sequence of the concepts in the form of an explanation. Two participants specifically referred to concept maps:

The concept map will be trying to show students if there is any connection or linkage from compound identities to double identities. (Participant 1A)

Eh...eeh Sir, drawing a concept map, I will just give you the order of concepts. (Participant 4B)

However, the participants' understanding of a concept map is of a linear order of how the concepts will be tackled. According to Plotz (2020), a concept map is a network of the hierarchical connectedness between various concepts displaying different associations between these concepts. The participants could not explain the relationship between trigonometric concepts, which could imply that participants' perceptions of KSM with regards to the concept map of FET trigonometry are partly sufficient.

Nevertheless, most participants (11 out of 12) showed knowledge of procedures by referring to processes and algorithms of tackling trigonometrical problems. Participant $5 \mathrm{C}$ stated:

Yes, the students need to know the formulae, which is the 'trig' ratios. The procedure involves writing the ratio first, substituting correct values and then using the calculator to get the final answer.

Therefore, it can be inferred that that participants' perceptions of KSM for effective teaching of trigonometry are sufficient as they perceive the subject content for effective teaching of trigonometry in accordance to the requirements of the CAPS document (DBE, 2011).

While most of the participants from the HP schools preferred using student-centered teaching strategies, many participants from the LP schools preferred using teacher-centered teaching strategies. Regarding to the reason for selecting a teaching strategy, five participants from the HP schools based their strategy selection on the possibility of involving the students during the learning process. Participant 3B stated:

I want students to be involved in the development of the concepts. Because most of these concepts were covered in grade 10.

However, three participants from the LP schools based their selection on the possibility of helping the students to remember the covered content. Participant 5B stated:

I think this strategy will be best, to show the students that the concepts they are learning in trigonometry are linked. I think if students discover on their own, they can easily remember the concepts. 
This finding is consistent with the findings of Lovitt and Clarke (2011), who indicated that some of the features of effective mathematics teaching includes active involvement of the students in the learning process. This finding could indicate that teachers' perceptions of KTS to use for effective teaching of trigonometry are partially as they still need to be encouraged to use more studentcentred approaches than teacher-centred approaches.

All the participants were able to state the goals of the lessons they were going to teach and indicated the pivotal role of having a goal for each of their lessons. Participant 5B claimed:

After the lesson my aim is that the students may be able to remember and use the two major trigonometric identities.

Some participants were able to identify concepts which they would use as prior knowledge for the lessons they were going to teach. Identification of students' prior knowledge by teachers could be a factor that influences effective teaching of trigonometry.

Only three participants could anticipate possible misconceptions students may have during their lessons:

There is the double identity $\cos 2 x$ which from my years of teaching I have seen that students tend to confuse the two. Some students think that $\cos 2 x=\cos 2 x+\sin 2 x$, which they confuse with the square identity. (Participant 1A)

Concerning the compound angle formula, the misconceptions I have encountered with previous students could be something like: $k \sin A=\sin k A$ and also $\sin A-\sin B=\sin (A-B)$. These two statements are based on misconceptions, first $k \sin A=\sin k A$ the misconception is that of considering coefficient of the sin function as the coefficient of angle A. (Participant 2A)

Probably students can write $-\tan x=\frac{-\sin x}{-\cos x}$. Haa... that's what I can think of for now. The misconception is having a negative on the numerator and a negative on the denominator. They forget that a negative number divided by a negative number gives a positive number. (Participant $5 \mathrm{~A})$

This finding reveals that many teachers create solutions to mathematical problems without understanding the reason for students' misconceptions, which may suggest that teachers' perceptions of KSC required for effective teaching of trigonometry are partly sufficient.

Most participants linked trigonometry with other mathematics topics. Nine participants indicated that they link trigonometry to coordinate geometry and three participants indicated that they link trigonometry to Euclidean geometry, while one participant linked trigonometry to algebra. Participant 4A mentioned:

I can link this particular topic with topics like Euclidean geometry and also the theorem which say

"line from center to midpoint of chord.

Unfortunately, the connection of trigonometry with real-life related examples were hardly mentioned. According to participant 2A:

This area does not have readily available real-life examples which can make students appreciate the topic. Therefore, I will not make use of real-life examples.

Also, no mention was made of connections between different topics or with other subjects such as physical sciences. This finding is consistent with Danişman and Tanişli (2017) revealing that the participants in their study were not cognizant of the distribution of topics such as probability across different grades or in other subjects. This finding may suggest that teachers' perceptions of $\mathrm{KC}$ for effective teaching of trigonometry are insufficient.

\subsection{Elements of PCK as Manifested in Teachers' Lesson Plans on Trigonometry}

Lesson planning is a major task for teachers, which they do as they transform the curriculum and the institutional expectations into practical tasks for the classroom (Tanni, 2012). Prescott et al. (2013) indicated that PCK can be disclosed by the use of lesson plans, because they summarise the trigonometrical content and tasks of the entire lesson in a perfect way. 
KSM is evident in lesson plans if the main ideas of trigonometry that are intended to be mastered by the students are included. Most of the lesson plans (22 of 24) had clear indications of the key concepts, for example, in lesson 1 of participant 3B "Derivation and use of the reduction formulae for $180^{\circ} \pm \theta$ and $360^{\circ} \pm \theta^{\prime \prime}$ are indicated in the lesson objectives, while the key concepts as indicated in the lesson objectives of lesson plan 2 of participant 2 are "use of special angles to calculate values of trigonometric ratios", and "derivation of the quotient and square identity". This finding might be an indication that most teachers use the CAPS document closely in their teaching (DBE, 2011), as the key trigonometric concepts in the lesson plans align with those stated in the CAPS document.

Most lesson plans (22 out of 24) included procedural knowledge, thus the knowledge of processes, and algorithms to tackle a trigonometrical problem. Participant 3B, for example, indicated procedures to follow in the main body of his first lesson plan, such as "use their calculators", "what they notice" and "how the angles are related" and a "summary on a Cartesian plane". This finding aligns with Mutton et al. (2011) claiming that pre-service teachers follow a prescribed format because they lack the experiential knowledge, while Shaw (2017) found that some experienced teachers do mental planning instead of written planning and prefer doing lesson plans which suit them instead of following a prescribed format. The findings could indicate that teachers appreciate the centrality of the lesson planning process and that a lesson plan is a core pillar of their teaching practice, which they believe defines good teaching. As the analysis of the lesson plans showed that most lesson plans include aspects of KSM such as key concepts and procedures, it can be deduced that sufficient KSM manifests itself in teachers' lesson plans on trigonometry.

All 24 lesson plans included lecturing as main teaching strategy. However, only 18 of these lesson plans included alternative strategies such as question and answer, teacher/student discussion and group work. In addition, 16 of the lessons included examples to explain the trigonometrical concepts. Leinhardt (2001) acknowledged that good teaching and sound conceptual explanations are grounded on the use of examples. This finding may indicate that partly sufficient KTS manifests itself in teachers' lesson plans on trigonometry.

Only two lesson plans displayed reflections on misconceptions. Addressing a possible misconception by including a task whereby students will substitute different angles into $\sin (A+B)$ and $\sin A+\sin B$ separately is evident in a question taken from lesson plan 2 of participant $2 B$ as illustrated in Figure 1.

Figure 1

Reflection on Misconceptions in Extract of Lesson Plan 2 of Participant 2B

Question: Chose any 10 pairs of angles, where one angle is for A and the other angle is for B. Substitute the angles into $\sin (A+B)$ and $\sin A+\sin B$ and record your results.

After few minutes, the teacher will ask the students their observations.

Participant 4A avoided a misconception in one of the examples he used in his lesson plan 1 as illustrated in Figure 2. 
Figure 2

Reflection on Misconceptions in Extract of Lesson Plan 1 of Participant $4 A$

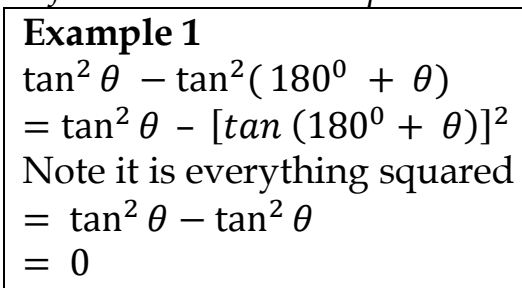

A possible misconception could be that students would write $\tan \left(180^{\circ}+\theta\right)^{2}$, which implies that it was the angle which was squared. Therefore, the inclusion of the statement "everything squared" clears the possible misconception. The finding that the lesson plans did not reveal major evidence of reflections on possible students' misconceptions is consistent with Halim and Mohd Meerah (2002) revealing that some pre-service teachers in their sample also showed unawareness of the students' misconceptions. A reason why many teachers do not reflect on misconceptions when planning trigonometry lessons could be that they are lacking knowledge of misconceptions in trigonometry or they view misconceptions as normal mistakes that students make. Another reason may be that the prescribed template does not explicitly make provision for teachers to reflect on possible misconceptions.

Nevertheless, many lesson plans (18 out of 24) showed traces of reflections on prior knowledge, which could assist students to connect known concepts with new ones. Lesson plan 1 of participant 2A started by revising trigonometrical identities covered in grade 11 before giving the students the identities which would involve double and compound angles as shown in Figure 3.

Figure 3

Reflection on Prior Knowledge in Extract of Lesson Plan 1 of Participant $2 \mathrm{~A}$

Participant 2A lesson plan 1 for grade 12

Introduction

Revise the trigonometrical ratios which were covered in grade 11. Give the students trigonometry identities where they prove applying the grade 11 trigonometrical concepts.

This finding is slightly different from Ramaligela et al. (2019), who revealed that the teachers in their sample introduced new content without establishing the prior knowledge. A reason could be that teachers are more comfortable with previous subject content at a lower level than new subject matter, and spend thus more time on revising that content.

Although many lesson plans included reflections on prior knowledge, only few reflections of misconceptions were evident. Therefore, these findings may suggest that partly sufficient KSC manifests itself in teachers' lesson plans on trigonometry. According to Baki and Arslan (2017), effective mathematics teachers must be aware of possible student misconceptions and difficulties by starting at the lesson planning level of each topic they will be going to teach. Sadler and Sonnert (2016) also agreed that teachers with a sound PCK have the ability to identify students' most common difficulties and are more likely to increase their students' subject knowledge.

All lesson plans linked trigonometry to other topics of the FET curriculum. For example, lesson plan 1 of participant 5B indicated that when proving trigonometrical identities, the algebraic concept of difference of two squares may be used as shown in Figure 4. 
Figure 4

Linking of Topics in Extract of Lesson Plan 1 of Participant $5 B$

\section{Teacher Activities}

Main Body

Teacher remind the students about the difference of two squares which is usually used in algebra. Teacher to state to the students that in trigonometry like in other mathematics topics we use concepts from other topics. Difference of two squares can be used when dealing with the reduction formulae.

However, none of the lessons showed how trigonometry fits into the curriculum. A reason may be that the participants did not consider the weightings outlined in the curriculum document at the stage of drafting lesson plans as these weightings do not play a role in designing single lesson plans, or that $\mathrm{KC}$ of the teachers with regards to lesson planning of trigonometry is fragmented. Thus, insufficient KC manifests itself in teachers' lesson plans on trigonometry. Nevertheless, sharing of information about the weighting of trigonometric topics could indicate to students the time needed to spend on trigonometry in their preparation for the final examination. This finding is inconsistent with Aydin et al. (2014) claiming that effective teaching involves teachers being aware of the sequencing of concepts and a rich repertoire of the horizontal and vertical connections.

\subsection{Elements of PCK as Manifested during Teaching of Trigonometry}

Conceptual understanding is a major component of effective teaching and refers to the knowledge of trigonometrical concepts and their connections (Rittle-Johnson \& Schneider, 2014). Most participants (10 out of 12) displayed a good understanding of the trigonometric concepts by transforming the content and making concepts comprehensible to the students during observations as evident by participant 2B in Vignette 1 as he explained the solution for question 2c.

Vignette 1

Observation of Conceptual Understanding of Participant $2 B$

Question 2c: If $\sin 2 \alpha=\frac{\sqrt{5}}{3}$ and $2 \alpha \in\left(90^{\circ} ; 270^{\circ}\right)$. Find $\sin \alpha$.

Student 1: Sir, can you please explain 2c from the homework. I was able to find the value of $x$ as -2 . But I could not find $\sin \alpha$

Participant 2B: In which quadrant is a? Why?

Student 2: It is in the first quadrant, because $2 \alpha$ is in the second quadrant.

Participant 2B: Exactly. The information which we have is for $2 \alpha$, that is to say the $x, y$ and $r$ values correspond to $2 \alpha$ and not to $\alpha$. Therefore, in this case is the following:

$$
\begin{aligned}
\cos 2 \alpha & =-\frac{2}{3} \\
1-2 \sin ^{2} \alpha & =-\frac{2}{3}
\end{aligned}
$$

then solve for it to finally get

$$
\sin \alpha=\sqrt{\frac{5}{6}}
$$

However, participants $4 \mathrm{~B}$ and $5 \mathrm{~A}$ had a few moments where they tried to explain the concepts, but without any success. For example, participant 5A just repeated the same explanations even after the students had indicated that they were not understanding. At the end, she indicated that another example would be given in the following lesson.

Nevertheless, most participants (10 out of 12) had a good understanding of the fundamental concepts of trigonometry. Participant $1 \mathrm{~B}$ could identify critical mathematical components within trigonometry that are fundamental for understanding the concepts, such as the reciprocal relationship of the trigonometric ratios, for example, that $\operatorname{cosec} \theta$ is the reciprocal of $\sin \theta$. The 
understanding of the fundamental trigonometric concepts by teachers may be a result of their teaching experience, which is supported by well-constructed teacher training programs (Aydin et al., 2014).

Only one participant, namely participant 3B did not really explain concepts, which made it difficult to establish her knowledge in this regard. A reason could be that he depends mainly on the worked examples in the textbooks and memoranda of past examination question papers. Another reason could be that he was not used to teach with someone observing the lesson or that he mainly focuses on using well-defined procedures when tackling mathematical problems. Nevertheless, most participants displayed evidence of conceptual understanding and knowledge of fundamental concepts, which may indicate that sufficient KSM manifests itself during teaching of trigonometry.

Using appropriate activities refers to teachers' awareness of the trigonometrical concepts that are covered at different grades and their cognizance of the requirements according to the CAPS document (DBE, 2011). During the lesson observations, it was observed that all participants used appropriate trigonometric tasks from the school textbooks and past examination question papers, which were consistent with the CAPS assessment guidelines (DBE, 2011). This finding is in agreement with Wong et al. (2012), arguing that teachers should be able to select activities from appropriate resources, and may indicate that teachers are aware of the relevant trigonometric activities for the grades that they are teaching as they make good use of relevant resources.

However, only one participant could notice students' alternative methods, which refers to the participants' awareness and acceptance of the other methods which the students will come up with to solve the problems. Participant $3 \mathrm{~B}$ noticed an alternative method from a student and she confirmed that it was correct and this made the contributing student felt valued as displayed in Vignette 2.

Vignette 2

Noticing Alternative Methods by Participant 3B

Question: Given that $\sin 23^{0}=\sqrt{t}$ determine $\cos 23^{0}$ in terms of $\mathrm{t}$.

Participant 3B: How do we proceed to answer this question?

Students: We use Pythagoras

Participant 3B:Yes, writing on the white board $x^{2}+(\sqrt{t})^{2}=1^{2}$

Participant 3B: Solving for $x$ what do we get?

Student 1: We get $=\sqrt{1-t}$, which gives $\cos 23^{0}=\sqrt{1-t}$

Alternative method

Student 2: Ma'am I worked it differently and I got the same answer.

Participant 3B: Interesting! How did you do it?

Student 2: We know that $\sin ^{2} x+\cos ^{2} x=1$

Therefore $\sin ^{2} 23^{0}+\cos ^{2} 23^{0}=1$

This gives $(\sqrt{t})^{2}+\cos ^{2} 23^{0}=1$

We then get $\cos ^{2} x=1-t$

Which gives $\cos x=\sqrt{1-t}$

Participant 3B: Well done, please clap hands for him. This is another method you can use.

According to Aydin et al. (2014), it is common that some teachers use only one method to avoid sharing the responsibility of constructing ideas with their students. However, Baumert et al. (2010) indicated that the breadth and depth of a teacher's conceptual understanding shape alternative representations and explanations, which result in the use of alternative measures.

In addition, none of the participants used real-life activities during the observed lessons. The use of real-life applications when teaching trigonometry could make the subject area meaningful to students, but the author admits that it is not easy at all times. The participants might also have had limited exposure to practical applications of trigonometry during their own teacher training 
period. Another reason could be that teachers put minimum effort in knowing the practical applications as such concepts are usually not examined during the end-of-the-year examinations.

Some participants (5 out of 12) used different teaching strategies during teaching of trigonometry, but most participants mainly depended on the lecture method. The use of different strategies of representations involves the methods and techniques that teachers utilize in demonstrations and descriptions to assist students in comprehending the trigonometrical concepts (Şahin et al., 2016). Participant 5A utilised explanations, and questions and answers as her teaching strategies. She gave students activities and then moved around assisting students who attempted the activities on their own. After 15 minutes she said "stop writing, let us mark the work. You will be telling me and I will be writing on the smart board". Teachers may prefer to use the lecture method as compared to the other methods because of the convenience it offers in terms of the overloaded annual teaching plan. By using the lecture method, more content can be covered in a short time. Another reason why the lecture method may be preferred could be as a result of how they were taught when they were still students at school or they might not have the desired level of knowledge of instructional strategies.

Nevertheless, all 12 participants created moments during which students could explain how they understand the trigonometric concepts. Participant 2A, in both his observed lessons, said to the students: "Please work with the person you are sitting with". Then, he continued: "if yourself and your neighbour don't understand, move around the room and find someone to help you". At times participant 4B allowed students to explain in their home language. In one of the lessons she stated: "Kutlano please explain you answer, you can use your home language, I don't want language to be a barrier here". Participant 5C also created opportunities for students to share their knowledge by urging students to give their different views. The finding indicates that teachers, who are able to create classroom environments of sharing knowledge in trigonometry, may create opportunities to clarify questions being asked. This finding is in agreement with Gür (2009) claiming that students' mathematical ability and confidence are enhanced, and their understanding of mathematical concepts improve if students are provided opportunities to explain to each other.

From this discussion, it could be inferred that partly sufficient KTS manifests itself during teaching of trigonometry. Participants in this study have diverse experiences. Some participants might consider it appropriate to focus on one teaching strategy that produced good student understanding in the previous years. Others might be uncomfortable with trying new strategies due to the pressure of trying to finish the syllabus. Şahin et al. (2016) also acknowledged that teachers in general, do not have the desired level of KTS.

KSC of participants during the teaching of trigonometry was ascertained if participants could address students' misconceptions and ways of thinking about trigonometry problems (Şahin et al., 2016). Moments where teachers enhanced students' understanding of trigonometric concepts by identifying and correcting misconceptions were identified in only few of the observed lessons (2 out of 24). Participant $3 \mathrm{~A}$ attended to a misconception during her lessons when a student had written co-ordinate $(3 ; 4)$ in the third quadrant. Participant $3 \mathrm{~A}$ asked: "How is $\mathrm{x}$ and $\mathrm{y}$ in the third quadrant?" She further stated: "Please be careful with this. You cannot have positive values in the third quadrant". This participant could also recognise students' ways of thinking about the concepts, which was evident from the questions she was asking as indicated in the Vignette 3. 
Vignette 3

Engagement with Students' Ways of Thinking by Participant $3 \mathrm{~A}$

Participant 3A: What is the answer to question 2a?

Students: -22

Participant 3A: Correct, but I want someone to explain the steps for the working?

Participant 3A: Yes, Student 1

Student 1: I used Pythagoras $x^{2}+(-3)^{2}=(5)^{2}$

$$
x=4
$$

I then substituted to get -22

Participant 3A: Any comments about the value of $x$ ?

Students: It's correct

Participant 3A: We are in which quadrant?

Students: Third quadrant.

Participant 3A: How is $x$ in the third quadrant?

Student 2: aaaa...hhh $x=-4$

Participant 3A: Yes, though the answer was correct it was not acceptable because the $x$-value was wrong.

In addition, participant $5 \mathrm{~B}$ wrote a trigonometric fraction on the white board and she wrote it with some working as shown in Vignette 4. She then asked the students to comment on the correctness of the working.

Vignette 4

Addressing a Misconception in Solving a Trigonometric Fraction by Participant $5 B$

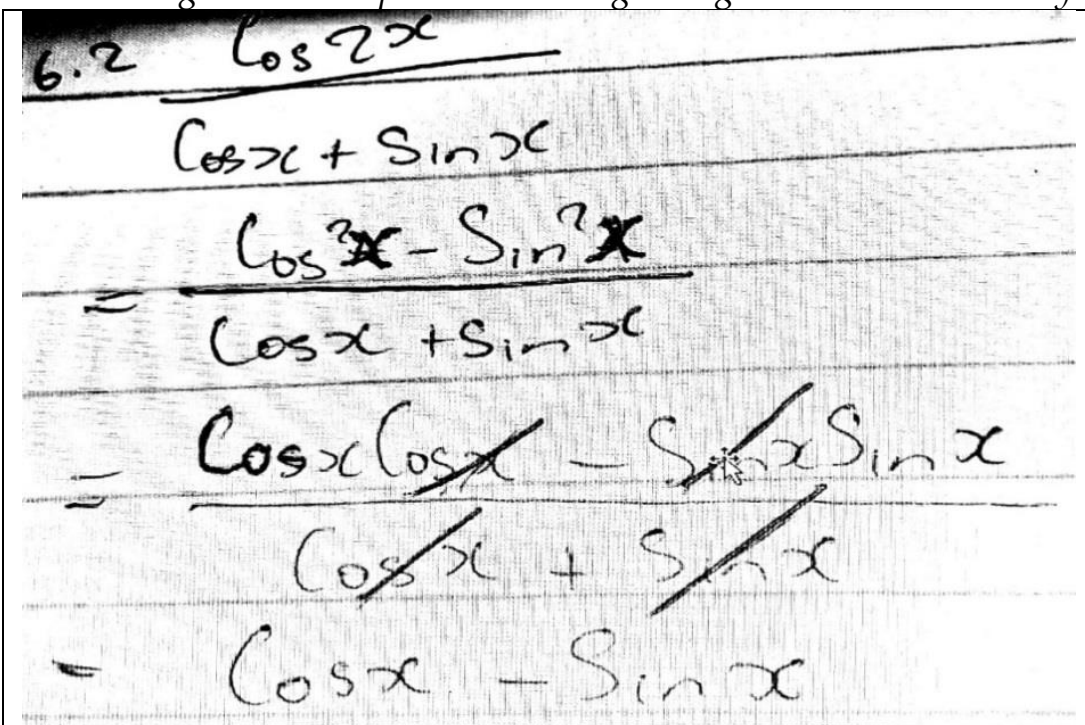

Student 1: Ma'am it is correct, because we get to the right hand side.

Participant 5B: Do not cancel like the way it is done on this working. You must follow the following steps.

$1^{\text {st }}$ step: apply double angle formula.... It's correct

$2^{\text {nd }}$ step: use difference of 2 squares to factorise

$3^{\text {rd }}$ step: cancel $(\cos x+\sin x)^{\prime \prime}$

Student 2: Does it matter how I arrive at the answer?

Participant 5B: Please be on the lookout, correct answer from a wrong working, its wrong

As only few participants showed evidence of addressing students' misconceptions and discussing students' ways of thinking, it could suggest that partly sufficient KSC manifests itself during teaching of trigonometry. According to Halim and Mohd Meerah (2002), teachers' knowledge of students' misconceptions is a result of the level of their content knowledge.

$\mathrm{KC}$ was evident as all participants could link trigonometric concepts vertically with those covered in the previous grades or signify to concepts to be covered in future grades during their 
teaching. For example, participant $1 \mathrm{~B}$ made the following statement in lesson observations as shown in Vignette 5.

Vignette 5

Linking Trigonometry Vertically by Participant $1 B$

Participant 1B: This result reminds you of what you did in grade 10.

Students: $\tan x=\sin x / \cos x$

Participant 5B gave a classwork example to his students as illustrated in Vignette 6. To simplify the numerator the students had to apply the reduction formulae, which was done in grade 11, and to simplify the denominator the students had to apply the compound formula, which was done in grade 12 .

Vignette 6

Linking Trigonometry Vertically by Participant 5B

Simplify the following to a single trigonometric ratio:

$$
\frac{\tan \left(180^{\circ}+x\right) \cos \left(360^{\circ}-x\right)}{\sin \left(180^{\circ}-x\right) \cos \left(90^{\circ}+x\right)+\cos \left(540^{\circ}+x\right) \cos (-x)}
$$

In addition, participant $6 \mathrm{~A}$ linked solving a trigonometric equation with factorization in algebra as shown in Vignette 7.

Vignette 7

Connecting Trigonometry with Other Topics by Participant $6 \mathrm{~A}$

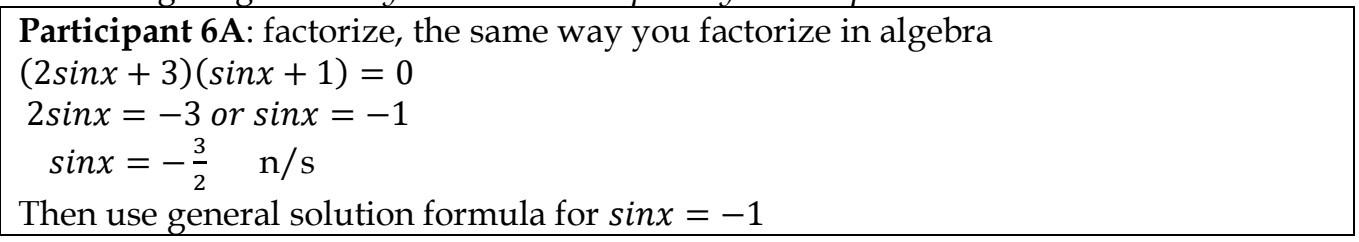

The reason why participants considered the vertical curriculum in their classwork examples might be as a result of teaching different grades. This finding is aligned with Correa et al. (2008), who found that the Chinese teachers could connect the content of different grades because they teach the same subject to different grades, while teachers in the United States of America who teach all subjects to the same grade could not make such connections. Unfortunately, none of the participants incorporated problem-solving classwork activities into their teaching of trigonometry although it is an important focal point of the CAPS document. The reason might be that the teachers instruct their students according to end-of-the-year examinations, which do not consider problem-solving questions, instead of giving sufficient attention to the specifications of the CAPS document. Therefore, it could imply that insufficient $\mathrm{KC}$ manifests itself during teaching of trigonometry.

\subsection{Elements of PCK as Manifested in Teachers' Assessment Tasks on Trigonometry}

All 24 classwork and homework tasks (two from each participant) displayed accurate key concepts of trigonometry for the grade that participants used to assess their students as specified by the CAPS document (DBE, 2011). Participant 2B gave his grade 11 students identities as shown in vignette 8 to prove as a classwork task. This task is appropriate for the grade 11 students and it was adapted from a source that is compliant with CAPS. 
Vignette 8

Accurate Trigonometry Concepts in a Classwork Task by Participant $2 B$
f) $\left(\tan \alpha+\frac{\cos \alpha}{\sin \alpha}\right) \sin \alpha=\frac{1}{\cos \alpha}$
g) $\frac{1}{1+\sin \beta}+\frac{1}{1-\sin \beta}=\frac{2}{\cos ^{2} \beta}$
h) $\frac{\cos x}{1+\sin x}+\tan x=\frac{1}{\cos x}$
i) $\left(\tan x+\frac{1}{\cos x}\right)^{2}=\frac{1+\sin x}{1-\sin x}$
j) $\frac{\sin ^{3} x+\sin x \cdot \cos ^{2} x}{\cos x}=\tan x$
k) $\left(\frac{1}{\cos \alpha}+\tan \alpha\right)\left(\frac{1}{\cos \alpha}-\tan \alpha\right)=1$

This finding indicates that teachers are aware of and knowledgeable about setting of assessment tasks in trigonometry. Thus, sufficient KSM manifests itself in teachers' assessment tasks on trigonometry.

All the participants also used appropriate assessment tasks for the grade they assessed and these activities were set according to the assessment guidelines for the topic of trigonometry, as stipulated in the CAPS document (DBE, 2011). However, most of these tasks were set from examples in textbooks and past examination papers, which did not cater for problem-solving or real-life related assessment tasks as suggested in the CAPS document. Wong and Kaur (2015) recommended that teachers must not only select appropriate assessment tasks, but also assess students' higher order knowledge, which can be achieved by using real-life problems. Therefore, it can be inferred that partly sufficient KTS manifests itself in teachers' assessment tasks on trigonometry.

Only few participants (4 out of 12) showed evidence of an awareness of the challenges that students may encounter when engaging with a trigonometry assessment task by providing differentiated tasks. For example, participant 1A stated: "the progressed students must only do questions 10.1 and 10.2. The other students you can do the work up to question 10". Participant 6A also requested the following concerning a classwork: "Please you can only do exercise 2 if I have marked your answers for exercise 1". However, a reason why teachers give the same classwork or homework tasks to all students could be as a result of their former teacher training overemphasizing inclusivity above differentiation between slow and fast students. This finding shows that partly sufficient KSC manifests itself in teachers' choice of assessment tasks on trigonometry.

All 24 classwork and homework tasks scrutinized included a full range of trigonometric topics and interconnected with the goals, key ideas and the resources available in relation to these topics as stipulated in the CAPS document (DBE, 2011). The contents of these assessment tasks also linked vertically with subject content covered in previous grades. For example, participant 2B asked his grade 11 students to prove the identity in Vignette 9. To prove this identity, the students had to apply the identity for $\tan x$, which they had done in grade 10.

Vignette 9

Assessment Task of Participant 2B Linking Trigonometry Vertically

h) $\frac{\cos x}{1+\sin x}+\tan x=\frac{1}{\cos x}$

However, as much as the participants taught students to gain knowledge, they also assessed students to pass the examinations. Many teachers may focus heavily on examinations in their teaching because of the conflicting demands of mandated common assessments advocated by 
DBE. Therefore, it can be inferred that partly sufficient KC manifests itself in teachers' choice of assessment tasks on trigonometry.

\section{Discussion}

A discussion of the findings on how PCK on trigonometry manifest itself in teachers' practice across the data collection methods follows next. Specifically, the findings regarding the four elements of PCK ascertained from the results, namely KSM, KTS, KSC and KC, are considered.

\subsection{Knowledge of Subject Matter}

KSM involved participants' understanding of the trigonometrical concepts and the procedures of unpacking them for the comprehension of the students (Walsh et al., 2017). The category KSM had three sub-categories: (1) keys concept indication; (2) indication of procedures; and (3) reflection of concepts and procedures.

The findings indicate that participants are aware of the key trigonometric concepts. Many participants displayed conceptual understanding of key trigonometric concepts during teaching and in their assessments. Also, all the assessment tasks of participants displayed accurate trigonometry concepts for the relevant grades. This finding is consistent with Ball (2000), who found that teachers with deep conceptual knowledge of a mathematical topic, for example, trigonometry equations, are able to present the content to their students in different ways. However, Walsh et al. (2017), found that the sample in their study had some gaps in their understanding of trigonometric concepts. The understanding of the fundamental trigonometric concepts by the participants may be a result of their teaching experiences supported by wellconstructed teacher training programs (Aydin et al., 2014).

Most of the participants displayed a sound knowledge of procedures with respect to the topic of trigonometry. This finding is in agreement with Rittle-Johnson and Schneider (2014) arguing that teachers must have an all-inclusive conceptual and procedural knowledge of the concepts of trigonometry to be effective. Also, the participants' lesson plans were done on a prescribed template of the DBE and showed clear indications of procedures to be followed. The findings could indicate that mathematics teachers appreciate the centrality of the lesson planning process and that lesson planning is a core pillar of their teaching practice, which they believe defines good teaching.

However, very few participants noticed students' alternative methods. No participant drew a concept map. The participants only gave explanations of the sequence of the concepts they were going to teach. Thus, their understanding of a concept map was of a linear order of how the concepts would be tackled. A possible reason could be that participants believe that mastering of only one method may reduce confusion among the students. This finding aligns with Aydin et al. (2014) considering this approach of only using one method as common with teachers who do not want to share the responsibility of constructing ideas with their students. Though, Baumert et al. (2010) indicate that the breadth and depth of teachers' conceptual understanding shape alternative representations and explanations that may result in the use of alternative measures.

Regardless of the drawback in terms of poor noticing of students' alternative methods and not using concept maps to teach trigonometry, the findings revealed that most participants have sufficient KSM of FET trigonometry. Therefore, it can be concluded that KSM on trigonometry manifests itself sufficient in teacher practices.

\subsection{Knowledge of Teaching Strategies}

KTS involved the approach that participants used in their teaching as they described, demonstrated, and unpacked the trigonometric concepts for the maximum comprehension of the students (Şahin et al., 2016). While Holtman et al. (2018) encourage teachers to use studentcentered strategies to accommodate more students in their teaching, the researcher found that most participants from LP schools used teacher-centered approaches. By focusing teaching on helping students to memorize concepts, might result in learning trigonometry without conceptual 
understanding. Teachers could have some knowledge of the teaching strategies to use to teach trigonometry, but those from the LP schools still need to be encouraged to use more studentcentered approaches than teacher-centered approaches.

Although all 24 lesson plans in this study contained teaching strategies of trigonometry, and many had examples, only half of the lesson plans from the LP schools showed evidence of reflections on alternative strategies. The teachers from the HP schools could be cognizant of the differences in their students' abilities and thus utilize alternative strategies, while the teachers from the LP schools might consider their students to be at the same performance levels.

With regard to the use of different strategies of representations, it was found that less than half of the participants used different teaching strategies. A reason why the participants preferred to only use certain teaching strategies could be that they have diverse experiences. Some might consider it appropriate to focus on one teaching strategy that produced good student understanding in the previous years, while others might be uncomfortable with trying new strategies due to the pressure of trying to finish the syllabus. This finding is in agreement with Şahin et al. (2016) acknowledging that teachers in general, do not have the desired level of knowledge of teaching strategies.

All 12 participants used appropriate activities in their teaching and assessments with regard to the grade being taught; and the activities were aligned with curriculum requirements. However, real-life examples were not used during teaching and assessing trigonometry. This finding does not align with Mutodi and Ngirande (2014), who established that participants in their study used concrete materials or real-life examples in mathematics to link the mathematics taught in the classroom with mathematics in the real world. According to Law et al. (2015), the use of real-life applications of trigonometry enhances students' understandings of the connection of ideas within mathematics and links between mathematics and other subjects. This finding could indicate that though it is important to link the teaching of trigonometry to the real world, participants do not find it easy to apply relevant real-life applications in their teaching. However, Wong et al. (2012) argue that for teachers to develop higher order knowledge, they need to use real-life related tasks to advance students' critical thinking skills.

Although participants used appropriate and correct activities during teaching and for assessment tasks, they lacked using sufficient alternative strategies or real-life related examples. This finding therefore indicates that KTS on trigonometry manifests itself partly sufficient in teachers' practice.

\subsection{Knowledge of Students' Conceptions}

KSC involved the participants' understanding of the students' prior knowledge, mistakes or misconceptions, and learning difficulties about trigonometry (Şahin et al., 2016). The commonalities between the participants were evident in five areas: (1) stating of goals of lessons; (2) awareness of prior knowledge; (3) limited addressing of misconceptions; (4) assistance of students with difficulties; and (5) lack of reflection on student difficulties.

All participants indicated an awareness of the pivotal role of having a goal for each of their lessons and all their lesson plans had clearly stated goals of what they had envisaged to teach. This finding is consistent with Olteanu (2017) claiming that there should be a connection between the lesson plan and the intended goal of the lesson to be presented. The trigonometry content, the teaching strategies, and the context included in lesson plans must align with the goals of the lesson. Thus, teachers must have KSC to ensure that the trigonometric content selected in lesson plans pitches at the level of students' comprehension.

Several lesson plans had evidence of teachers' reflection on students' prior knowledge. This finding could indicate that some teachers might be aware of baseline concepts that can be used as prior knowledge to introduce new trigonometry lessons. Therefore, teachers' KSC should be developed as students' prior knowledge lays the base for their future learning (Campbell et al., 
2014). Also, teachers with good KSC are able to address misconceptions, which students could have extended to new subject content in trigonometry as a result of past learning difficulties.

Although none of the lesson plans included any difficulties students could experience with regard to new content, the researcher was skeptical to put too much weight on the lesson plans. The researcher acknowledges that lesson plans are written by the same teachers who use them and that lesson plans do not fully account for what is taught in a classroom. Many experienced teachers may teach some subject content instinctively in the classroom without including it in their lesson plan. Nevertheless, most participants preferred using extra classes as a way of assisting students with difficulties rather than other approaches, such as alternative teaching strategies or peerassistance. Also, most of the lesson plans excluded possible misconceptions students might encounter with the content to be covered. Only two participants could address student misconceptions, displayed expectations according to the students' performance, and discussed students' ways of thinking. This finding might indicate that the participants have insufficient KSC, especially in the light of Wilson et al. (2005) recommending that teachers should have an extensive knowledge of the students they are teaching to ensure good teaching.

Although most lesson plans included assessment instruments, they were predominately restricted to classwork and homework taken from the textbook or past examination papers. Classwork and homework are teacher-assigned assessments, which cater for procedural understanding by allowing students to practice, reinforce, and to consolidate the trigonometry content taught in class (Kaur, 2011). The finding could indicate that participants are not aware of other assessment instruments such as investigations or projects that are more student-centered and which allow for enhancement of conceptual understanding.

In precis, all the participants in the study were able to state goals for their lessons, and many were aware of the important role prior knowledge plays in teaching new trigonometry content. However, participants did not indicate any learning difficulties students might experience with trigonometric content and predominantly utilized extra classes as an approach to assist students with learning difficulties. Also, most participants were not aware of the misconceptions in trigonometry and used teacher-centered assessment instruments. Subsequently, it can be inferred that KSC on trigonometry manifests itself partly sufficient in teachers' practice.

\subsection{Knowledge of Curriculum}

KC referred to the participants' understanding of the range of mathematical topics that are included in the curriculum and how they are connected to trigonometry (Appova \& Taylor, 2020). There were four commonalities between the participants: (1) linking of trigonometry with other topics; (2) non-use of real-life examples; (3) linking trigonometry vertically; and (4) fitting trigonometry into the curriculum.

While Prescott et al. (2013) indicated that effective teachers should display, among others, a mastery of $\mathrm{KC}$, the researcher found that slightly more than half of the participants were able to connect trigonometry to algebra. No connections were made to other disciplines. Only a few participants could fit trigonometry into the curriculum, but tended to compartmentalize certain topics in trigonometry. No horizontal connections made between topics were evident. However, all the participants were able to link trigonometry vertically, especially by linking new trigonometry concepts with the concepts covered in the previous grade and the next grade. This finding is inconsistent with Aydin et al. (2014) claiming that effective teaching involves teachers being aware of the sequencing of concepts; and having knowledge of a rich repertoire of the horizontal and vertical connections between mathematics content. This finding could indicate that the curriculum is silent about linking trigonometric topics across different disciplines although trigonometry is applicable for instance in Physics when resolving forces; and in Geography when calculating bearings.

While Law et al. (2015) revealed that the use of real-life applications by teachers assist students to relate mathematics with other subjects, the researcher found that most of the participants did 
not use real-life applications in their teaching of trigonometry.. The participants might have focused too much on procedural knowledge included in past examination papers, without paying attention to application questions that could enhance conceptual knowledge. Correa et al. (2008) also found that teachers attempt to align their daily assessments to the way past examination papers are set and do by not including real-life related assessments. Therefore, this finding may infer that KC on trigonometry manifests itself insufficient in teachers' practice.

\section{Conclusion}

Although trigonometry offers students the opportunity to develop reasoning skills, many teachers find it difficult to teach due to their levels of PCK. This study established how PCK on trigonometry manifests itself in teachers' practice. The elements of PCK on trigonometry manifested in teacher practices varied from one another in terms of levels of sufficiency as follows: (1) KSM manifested itself sufficient; (2), KTS manifested itself partly sufficient; (3) KSC manifested itself partly sufficient; and (4) manifested itself insufficient.

Teachers are aware of the importance of the knowledge of mathematical topics in trigonometry, but these topics could be emphasized more in their teaching. Students should also be showed how to use visual representations such as concept maps to relate topics with each other. Teachers should also not only focus on students' procedural knowledge, but also on their conceptual understanding of trigonometry topics.

Teachers need to cultivate in students an appreciation for the relevance of learning mathematics through using real-life examples and practical applications of trigonometry concepts during the learning process. They should share alternative teaching strategies of teaching trigonometric topics, which include student-centered approaches, with other teachers in order to elicit students' conceptual understanding.

Teachers need to be sensitized about the importance of identifying students' misconceptions in their learning of trigonometry reflecting more on students' difficulties. Teachers could benefit from in-service training and how to use examination papers as a source for assessment to develop KSC.

Lastly, teacher education programs should show pre-service teachers how trigonometry fits into the mathematics curriculum, how to infuse real-life applications in different trigonometric topics, and also how to link trigonometric content with other topics. Such training will give teachers confidence to teach mathematics when entering the teaching profession. Teachers also need guidance not only on how to link trigonometric topics vertically across different grades, but also horizontally with other mathematics topics.

This study focused on a small sample of six township schools from one district in Gauteng, South Africa. Different trends may have occurred in other educational contexts. This study also concentrated on how the elements of PCK on only one mathematics section relate to the MKT model, namely trigonometry. Thus, the generalization of findings to other mathematics sections, or even other subject disciplines, must be treated with caution. Other PCK models may also be investigated. A follow-up longitudinal study is recommended to monitor teachers' PCK development over a period of time. As the study mainly produced qualitative data, quantitative data may assist in measuring the level of PCK teachers possess in more depth.

Many questions encountered, but outside the scope of this study, may be of interest for further research. For example: Why do some teachers not use alternative strategies for teaching trigonometry? Why are topics in trigonometry compartmentalized within the curriculum by some teachers? Why do some teachers fail to make horizontal connections between topics? Why when trigonometry is so very useful in the sciences, do some teachers not include real-life tasks? Do teachers believe that mastering only one method to teach trigonometry will reduce confusion?

This study adds to few studies in PCK in mathematics by providing empirical evidence on how PCK on trigonometry manifests itself in teachers' practice. The revealing of different levels of sufficiency between the elements of PCK manifested in teachers' practice may form a useful basis for the planning of developmental opportunities to address shortcomings in PCK on trigonometry 
in teachers' practice. This study also offers an adaption of the MKT model that can be used not only to analyze PCK in mathematics in general, but also topic-specific PCK. In addition, this study creates an awareness of the importance of using real-life applications in the teaching of trigonometry, which fosters an appreciation for the relevance of mathematics. Lastly, this study creates a platform for large-scale research on teachers' PCK development pertaining to trigonometry or any other mathematics section.

Acknowledgement 1. I thank Gauteng Department of Education, the subject advisor of Ekurhuleni North District and principals of schools for consent to conduct the research. I am also grateful to all mathematics teachers agreed to participate in the study. Lastly, much appreciation is expressed to Bright Magabvu, a former master student at the University of Johannesburg, who assisted with data collection.

Acknowledgement 2. This paper is the extended version of a contribution to the second International Conference of Pedagogical Research (ICOPR) which was held on May 15-16, 2021 with the hostage of Universiti Utara Malaysia.

\section{References}

Appova, A., \& Taylor, C. E. (2020). Providing opportunities to develop prospective teachers' pedagogical content knowledge. In A Appova, R. M. Welder, \& Z. Feldman (Eds.), Supporting Mathematics Teacher Educators' Knowledge and Practices for Teaching Content to Prospective (Grades K-8) Teachers. Special Issue: The Mathematics Enthusiast (Vol 17. pp. 673-724). ScholarWorks: University of Montana.

Aydin, S., Friedrichsen, P. M., Boz, Y., \& Hanuscin, D. L. (2014). Examination of the topic-specific nature of pedagogical content knowledge in teaching electrochemical cells and nuclear reactions. Chemistry Education Research and Practice, 15(4), 658-674. https://doi.org/10.1039/C4RP00105B

Baki, M., \& Arslan, S. (2017). Effects of mathematics content knowledge on mathematics pedagogical content knowledge. Journal of Teacher Education and Educators, 6(2), 53-68.

Ball, D. L. (2000). Bridging practices intertwining content and pedagogy in teaching and learning to teach. Journal of Teacher Education, 51(3), 241-247. https:// doi.org/10.1177/0022487100051003013

Baumert, J., Kunter, M., Blum, W., Brunner, M., Voss, T., Jordan, A., Klusmann, U., Krauss, S., Neubrand, M., \& Tsai, Y. M. (2010). Teachers' mathematical knowledge, Cognitive activation in the classroom, and student progress. American Educational Research Journal, 47(1), 133-180. https://doi.org/10.3102/0002831209345157

Brijlall, D., \& Maharaj, A. (2014). Exploring support strategies for high school mathematics teachers from underachieving schools. International Journal of Educational Sciences, 7(1), 99-107. https://doi.org/10.1080/09751122.2014.11890173

Campbell, P. F., Nishio, M., Smith, T. M., Clark, L. M., Conant, D. L., Rust, A. H., Neumayer DePiper, J., Jones Frank, T., Griffin, M. J., \& Choi, Y. (2014). The relationship between teachers' mathematical content and pedagogical knowledge, teachers' perceptions, and student achievement. Journal for Research in Mathematics Education, 45(4), 419-459. https://doi.org/10.5951/jresematheduc.45.4.0419

Carrillo-Yañez, J., Climent, N., Montes, M., Contreras, L. C., Flores-Medrano, E., Escudero-Ávila, D., Vasco, D., Rojas, N., Flores, P., Aguilar-González, Á., Ribeiro, M., \& Muñoz-Catalán, M. C. (2018). The mathematics teacher's specialised knowledge (MTSK) model. Research in Mathematics Education, 20(3), 236-253. https://doi.org/10.1080/14794802.2018.1479981

Chan, K. K. H., \& Yung, B. H. W. (2018). Developing pedagogical content knowledge for teaching a new topic: more than teaching experience and subject matter knowledge. Research in Science Education, 48(2), 233-265. https:// doi.org/10.1007/s11165-016-9567-1

Chapman, O. (2012). Challenges in mathematics teacher education. Journal of Mathematics Teacher Education, 15(4), 263-270. https:// doi.org/10.1007/s10857-012-9223-2

Chick, H., \& Beswick, K. (2018). Teaching teachers to teach Boris: A framework for mathematics teacher educator pedagogical content knowledge. Journal of Mathematics Teacher Education, 21(5), 475-499. https://doi.org/10.1007/s10857-016-9362-y

Cho, J. Y., \& Lee, E.-H. (2014). Reducing confusion about grounded theory and qualitative content Analysis: Similarities and differences. The Qualitative Report, 19(32), 1-20.

Correa, C. A., Perry, M., Sims, L. M., Miller, K. F., \& Fang, G. (2008). Connected and culturally embedded 
beliefs: Chinese and US teachers talk about how their students best learn mathematics. Teaching and Teacher Education, 24(1), 140-153. https://doi.org/10.1016/j.tate.2006.11.004

Danişman, S., \& Tanişli, D. (2017). Examination of mathematics teachers' pedagogical content knowledge of probability. Malaysian Online Journal of Educational Sciences, 5(2), 16-34.

Depaepe, F., Verschaffel, L., \& Kelchtermans, G. (2013). Pedagogical content knowledge: A systematic review of the way in which the concept has pervaded mathematics educational research. Teaching and Teacher Education, 34, 12-25. https:/ / doi.org/10.1016/j.tate.2013.03.001

Department of Basic Education. (2011). Curriculum and Assessment Policy Statement: Further Education and Training Phase. Grades 10-12 Mathematics. https://www.education.gov.za/Portals/0/CD/National Curriculum Statements and Vocational/CAPS FET _ MATHEMATICS _ GR 10-12 _ Web_1133.pdf?ver=2015-01-27-154314-253

Fiallo, J., \& Gutiérrez, A. (2017). Analysis of the cognitive unity or rupture between conjecture and proof when learning to prove on a grade 10 trigonometry course. Educational Studies in Mathematics, 96(2), $145-$ 167. https://doi.org/10.1007/s10649-017-9755-6

Gerhana, M. T. C., Mardiyana, M., \& Pramudya, I. (2017). The effectiveness of project based learning in trigonometry. Journal of Physics: Conference Series, 895, 012071. https://doi.org/10.1088/17426596/895/1/012027

Gould, D., \& Schmidt, D. A. (2010). Trigonometry comes alive through digital storytelling. The Mathematics Teacher, 10 (4), 296-301. https://doi.org/10.5951/MT.104.4.0296

Goodnough, K., Azam, S., \& Wells, P. (2019). Adopting drone technology in STEM (Science, Technology, Engineering, and Mathematics): An examination of elementary teachers' pedagogical content knowledge. Canadian Journal of Science, Mathematics and Technology Education, 19(4), 398-414. https://doi.org/10.1007/s42330-019-00060-y

Gür, H. (2009). Trigonometry learning. New Horizons in Education, 57(1), 67-80.

Halim, L., \& Mohd Meerah, S. (2002). Science trainee teachers' pedagogical content knowledge and its influence on physics teaching, Research in Science $\mathcal{E}$ Technological Education, 20(2), 215-225. https://doi.org/10.1080/0263514022000030462

Hauk, S., Toney, A., Jackson, B., Nair, R., \& Tsay, J. (2014). Developing a model of pedagogical content knowledge for secondary and post-secondary mathematics instruction. Dialogic Pedagogy: An International Online Journal, 2, 16-40. https:// doi.org/10.5195/dpj.2014.40

Hill, H. C., Ball, D. L., \& Schilling, S. G. (2008). Unpacking pedagogical content knowledge: Conceptualizing and measuring teachers' topic-specific knowledge of students. Journal for Research in Mathematics Education, 39(4), 372-400. https://doi.org/10.2307/40539304

Holtman, L., Martin, J., \& Mukuna, R. (2018). Factors influencing the in-service programmes: Case study of teachers with learner-centred strategies in Blue Watersi setting. South African Journal of Education, 38(3), 114. https:// doi.org/10.15700/saje.v38n3a1429

Kaur, B. (2011). Mathematics homework: A study of three grade eight classrooms in Singapore. International Journal of Science and Mathematics Education, 9(1), 187-206. https:/ / doi.org/10.1007/s10763-010-9237-0

Keller, M. M., Neumann, K., \& Fischer, H. E. (2017). The impact of physics teachers' pedagogical content knowledge and motivation on students' achievement and interest. Journal of Research in Science Teaching, 54(5), 586-614. https://doi.org/10.1002/tea.21378

Kleickmann, T., Richter, D., Kunter, M., Elsner, J., Besser, M., Krauss, S., \& Baumert, J. (2013). Teachers' content knowledge and pedagogical content knowledge: The role of structural differences in teacher education. Journal of Teacher Education, 64(1), 90-106. https://doi.org/10.1177/0022487112460398

Kleickmann, T., Richter, D., Kunter, M., Elsner, J., Besser, M., Krauss, S., Cheo, M., \& Baumert, J. (2015). Content knowledge and pedagogical content knowledge in Taiwanese and German mathematics teachersitle. Teaching and Teacher Education, 46, 115-126. https:/ / doi.org/10.1016/j.tate.2014.11.004

Krause, L. S., \& Prinsloo, M. (2016). Translanguaging in a township primary school: Policy and practice. Southern African Linguistics and Applied Language Studies, 34(4), 347-357. https://doi.org/10.2989/16073614.2016.1261039

Law, F. F., Shahrill, M., \& Mundia, L. (2015). Investigating students' conceptual knowledge and procedural skills in the learning of college level trigonometry. Research Journal of Applied Sciences, Engineering and Technology, 9(11), 952-962. https:// doi.org/10.19026/rjaset.9.2588

Lee, J., Hamideh, D., \& Nebeker, C. (2019). Qualifying and quantifying the precision medicine rhetoric. BMC Genomics, 20(1), 868. https:// doi.org/10.1186/s12864-019-6242-8

Leinhardt, G. (2001). Instructional explanations: A commonplace for teaching and location for contrast. In V. 
Richardson (Ed.), Handbook of research on teaching (4th ed., pp. 333-357). Washington, DC: American Educational Research Association.

Loewenberg Ball, D., Thames, M. H., \& Phelps, G. (2008). Content knowledge for teaching: what makes it special? Journal of Teacher Education, 59(5), 389-407. https:// doi.org/10.1177/0022487108324554

Lovitt, C. \& Clarke, D. (2011). The features of a rich and balanced mathematics lesson: Teacher as designer. Educational Designer, 1(4), 1-25. https://www.educationaldesigner.org/ed/volume1/issue4/article15/pdf/ed_1_4_lovitt_clarke_11.pdf

Merriam, S. B., \& Tisdell, E. J. (2015). Qualitative Research - A guide to design and implementation (4th edition). Jossey-Bass Inc.

Mishra, P., \& Koehler, M. J. (2006). Technological pedagogical content knowledge: A framework for teacher knowledge. Teachers College Record, 108(6), 1017-1054. https:// doi.org/10.1111/j.1467-9620.2006.00684.x

Mutodi, P., \& Ngirande, H. (2014). The influence of students` perceptions on mathematics performance. A case of a selected high school in South Africa. Mediterranean Journal of Social Sciences, 5(3), 431-445. https://doi.org/10.5901/mjss.2014.v5n3p431

Mutton, T., Hagger, H., \& Burn, K. (2011). Learning to plan, planning to learn: The developing expertise of beginning teachers. Teachers and Teaching, 17(4), 399-416. https:// doi.org/10.1080/13540602.2011.580516

O’Meara, N., Fitzmaurice, O., \& Johnson, P. (2017). Old habits die hard: An uphill struggle against rules without reason in mathematics teacher education. European Journal of Science and Mathematics Education, 5(1), 91-109.

Ogbonnaya, U. I., \& Mogari, D. (2014). The relationship between grade 11 students' achievement in trigonometric functions and their teachers' content knowledge. Mediterranean Journal of Social Sciences, 5(4), 443-451. https://doi.org/10.5901/mjss.2014.v5n4p443

Olteanu, C. (2017). Reflection-for-action and the choice or design of examples in the teaching of mathematics. Mathematics Education Research Journal, 29(3), 349-367. https:// doi.org/10.1007/s13394-017-0211-9

Phelps, G., \& Howell, H. (2016). Assessing mathematical knowledge for teaching: The role of teaching context. The Mathematics Enthusiast, 13(1 \& 2), 52-70.

Plotz, T. (2020). Are concept maps a valid measurement tool for conceptual learning? A cross-case study. EURASIA Journal of Mathematics, Science and Technology Education, 16(1), 1-22. https://doi.org/10.29333/ejmste/110174

Prescott, A., Bausch, I., \& Bruder, R. (2013). TELPS: A method for analysing mathematics pre-service teachers' pedagogical content knowledge. Teaching and Teacher Education, 35, 43-50. https:// doi.org/10.1016/j.tate.2013.05.002

Ramaligela, S. M., Ogbonnaya, U. I., \& Mji, A. (2019). Comparing pre-service teachers' PCK through 9E instructional practice: A case of mathematics and technology pre-service teachers. Africa Education Review, 16(3), 101-116. https:// doi.org/10.1080/18146627.2016.1241668

Rittle-Johnson, B., \& Schneider, M. (2014). Developing conceptual and procedural knowledge of mathematics. In R. Cohen Kadosh \& A. Dowker (Eds.), Oxford handbook of numerical cognition (pp. 11021118). Oxford University Press. https:// doi.org/10.1093/oxfordhb/9780199642342.013.014

Rollnick, M., Bennett, J., Rhemtula, M., Dharsey, N., \& Ndlovu, T. (2008). The Place of subject matter knowledge in pedagogical content knowledge: A case study of South African teachers teaching the amount of substance and chemical equilibrium. International Journal of Science Education, 30(10), 13651387. https://doi.org/10.1080/09500690802187025

Rule, P., \& Vaughn, J. (2011). Your guide to case study research. Van Schaik Publishers.

Sadler, P. M. \& Sonnert, G. (2016). Understanding misconceptions: Teaching and learning in middle school physical science. American Educator, 40(1), 26-32.

Şahin, Ö., Gökkurt, B., \& Soylu, Y. (2016). Examining prospective mathematics teachers' pedagogical content knowledge on fractions in terms of students' mistakes. International Journal of Mathematical Education in Science and Technology, 47(4), 531-551. https:// doi.org/10.1080/0020739X.2015.1092178

Saldana, J. (2013). The coding manual for qualitative researchers (Second edition). SAGE Publications Ltd.

Sampaio Figueiredo, H. R., \& Batista, I. D. L. (2018). Mathematics history and cognitive values on a didactic sequence: Teaching trigonometry. Journal of Research in Mathematics Education, 7(3), 311-332. https://doi.org/10.17583/redimat.2018.2727

Shaw, R. D. (2017). I can hardly wait to see what I am going to do today: Lesson planning perspectives of experienced band teachers. Contributions to Music Education, 42, 129-152.

Shulman, L. (1987). Knowledge and teaching: Foundations of the new reform. Harvard Educational Review, 57(1), 1-23. https://doi.org/10.17763/haer.57.1.j463w79r56455411 
Shulman, L. S. (1986). Those who understand: Knowledge growth in teaching. Educational Researcher, 15(2), 4-14. https:// doi.org/10.3102/0013189X015002004

Şimşek, N., \& Boz, H. (2016). Analysis of pedagogical content knowledge studies in the context of mathematics education in Turkey: A meta-synthesis study. Educational Sciences: Theory \& Practice, 16(3), 799-826. https://doi.org/10.12738/estp.2016.3.0382

Speer, N. M., King, K. D., \& Howell, H. (2015). Definitions of mathematical knowledge for teaching: Using these constructs in research on secondary and college mathematics teachers. Journal of Mathematics Teacher Education, 18(2), 105-122. https://doi.org/10.1007/s10857-014-9277-4

Tanni, M. (2012). Teacher trainees' information acquisition in lesson planning. Information Research: An International Electronic Journal, 17(3), Online. http://informationr.net/ir/17-3/paper530.html\#.YPkEsgzbIU

Walsh, R., Fitzmaurice, O., \& O'Donoghue, J. (2017). What subject matter knowledge do second-level teachers need to know to teach trigonometry? An exploration and case study. Irish Educational Studies, 36(3), 273-306. https:// doi.org/10.1080/03323315.2017.1327361

Wilson, P. S., Cooney, T. J., \& Stinson, D. W. (2005). What Constitutes good mathematics teaching and how it develops: Nine high school teachers' perspectives. Journal of Mathematics Teacher Education, 8(2), 83-111. https://doi.org/10.1007/s10857-005-4796-7

Wong, A. F. L., Chong, S., Choy, D., \& Lim, K. M. (2012). Investigating changes in pedagogical knowledge and skills from pre-service to the initial year of teaching. Educational Research for Policy and Practice, 11(2), 105-117. https://doi.org/10.1007/s10671-011-9108-7

Wong, L. F., \& Kaur, B. (2015). A study of mathematics written assessment in Singapore secondary schools. The Mathematics Educator, 16(1), 19-44.

Yang, D. C., \& Sianturi, I. A. (2017). An Analysis of Singaporean versus Indonesian textbooks based on trigonometry content. EURASIA Journal of Mathematics, Science and Technology Education, 13(7), 3829-3846. https://doi.org/10.12973/eurasia.2017.00760a 